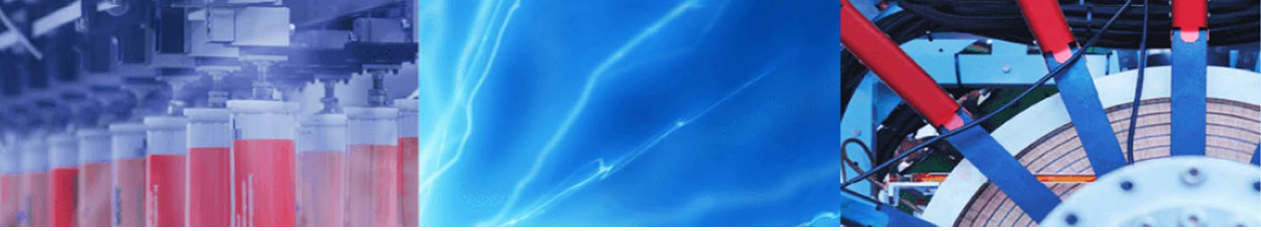

Research Article

\title{
Synthesis of fatty phenylthiosemicarbazide from underutilized Sesamum indicum seed oil: a promising corrosion inhibitor of carbon steel in developing country
}

\author{
Adewale Adewuyi ${ }^{1}$ - Abe Oluwaseyifunmi ${ }^{2}$ - Shiva Shanker Kaki ${ }^{3} \cdot$ Rotimi A. Oderinde $^{2}$
}

(c) Springer Nature Switzerland AG 2019

\begin{abstract}
Fatty phenylthiosemicarbazide (FP) was synthesized from Sesamum indicum seed oil (SO) via simple reaction mechanism, which was characterized using Fourier transform infrared and proton nuclear magnetic resonance ( $\left.{ }^{1} \mathrm{HNMR}\right)$. Fatty acid composition of SO was examined using gas chromatography (GC) coupled with flame ionization detector while FP was evaluated for its ability to inhibit corrosion in carbon steel using weight loss method. Quantum chemical computation using density functional theory was applied to gain theoretical insight on the inhibition capacity of FP. The result of the GC revealed the most dominant fatty acid in SO to be C18:2 (43.77\%) while the least was C16:1 (0.10\%). FP exhibited a corrosion inhibition efficiency of $62.55 \%$ at room temperature but increased to $99.57 \%$ at $303 \mathrm{~K}$, which obeyed Langmuir isotherm. The $\Delta G_{\text {ads }}^{\circ}$ value revealed the process to be spontaneous while both $\Delta H_{\text {ads }}^{\circ}\left(-1.088 \mathrm{~kJ} \mathrm{~mol}^{-1}\right)$ and $\Delta S^{\circ}$ $\left(-0.015 \mathrm{~kJ} \mathrm{~mol}^{-1} \mathrm{~K}^{-1}\right)$ suggested an exothermic process. The lowest unoccupied molecular orbital and highest occupied molecular orbital were distributed over the molecule of FP with an activation energy of $25.606 \mathrm{~kJ} \mathrm{~mol}^{-1}$. The current study presents FP as a promising corrosion inhibitor, which can replace synthetic compounds from petrochemicals used as corrosion inhibitors in developing countries.
\end{abstract}

Keywords Carbon steel · Corrosion inhibition · DFT · NMR · Sesamum indicum

\section{Introduction}

Corrosion is a serious problem, which requires urgent attention [1]. The effect of corrosion may be direct or indirect. The direct effect may be the immediate effect corrosion has on materials, which are daily used; this direct effect is seen at home on household devices, automobile, outdoor furniture and metal containing devices. The indirect effect may be the negative impact of corrosion cost incurred by producers and suppliers of goods and services, which they pass on consumers. Efforts have been made to control the damage caused by corrosion [2-5]. Some of the reported efforts include appropriate selection of material, surface coating, effective material design, use of inhibitors and electrical protection. The tendency of any material to corrode has been shown to depend on its structure and composition while presence of air, moisture, impurities and gases such as Sulphur and carbon dioxide have contributed greatly to the process of corrosion [6]. The use of corrosion inhibitors as proved to be effective in corrosion control over time [7]. Moreover, a number of the known corrosion inhibitors are synthetic compounds with encouraging performance; however, despite their reported effectiveness, they have some drawbacks such as being expensive, toxic, non-biodegradable and unsustainable $[8,9]$. This has created the need for safer, cheap, sustainable and biodegradable sourced corrosion inhibitors.

\footnotetext{
$\triangle$ Adewale Adewuyi, walexy62@yahoo.com | 'Department of Chemical Sciences, Faculty of Natural Sciences, Redeemer's University, Ede, Osun State, Nigeria. ${ }^{2}$ Industrial Unit, Department of Chemistry, University of Ibadan, Ibadan, Oyo State, Nigeria. ${ }^{3}$ Centre for Lipid Science and Technology, CSIR-Indian Institute of Chemical Technology, Hyderabad 500007, India.
} 
Use of plant extracts and their modified forms has been reported as green and effective corrosion inhibitors [10]. Plant extract such as plant seed oil can serve this purpose. They are from renewable sources, biodegradable and can be modified to form compounds or mixtures with improved properties, which can serve as corrosion inhibitors and as a result can replace synthetic compounds from petrochemicals used as corrosion inhibitors [11, 12]. Most of the synthetic petrochemical products are environmentally unfriendly and when used as corrosion inhibitors may find their ways into water, food chain and soil, which further discourages their use as inhibitors. The aim of this study is to produce FP from SO and investigate its use as corrosion inhibitor of carbon steel in acidic medium. DFT technique was used to evaluate the capacity of FP to inhibit corrosion in carbon steel, which further helps in understanding the mechanism by which this is achieved.

\section{Experimental}

\subsection{Materials}

Acetone, methanol, $\mathrm{HCl}$, hexane, phenylhydrazine, anhydrous sodium sulphate, potassium thiocyanate, $\mathrm{NaOH}$, and all other chemicals used in this study were purchased from Aldrich Chemical Co., England. The seed was purchased from a market in Ibadan, Oyo State, Nigeria. The seed was air dried, ground into powder and kept in an airtight container until ready for analysis. Oil was extracted from the seed of Sesamum indicum using $\mathrm{n}$-hexane in a soxhlet extractor for $10 \mathrm{~h}$ as previously described by Adewuyi et al. [13].

\subsection{Fatty acid composition}

The fatty acid composition of SO was determined as fatty acid methyl ester. This was prepared using $2 \%$ sulphuric acid in methanol. The ester was extracted into ethyl acetate, washed free of acid and dried over anhydrous sodium sulphate. The dried ester was further concentrated on a rotary evaporator and finally analyzed using GC. The GC analysis was achieved using an Agilent 6850 series GC equipped with FID detector. The column temperature was initially maintained as $160^{\circ} \mathrm{C}$ for $2 \mathrm{~min}$ and gradually increased to $230^{\circ} \mathrm{C}$ at $4{ }^{\circ} \mathrm{C} / \mathrm{min}$ and finally maintained at $230^{\circ} \mathrm{C}$ for 10 min using a DB-225 capillary column. The detector and injector temperatures were maintained at $250{ }^{\circ} \mathrm{C}$ and $230^{\circ} \mathrm{C}$; respectively at a split ratio of $50: 1$ and the carrier gas being nitrogen at a flow rate of $1.5 \mathrm{~mL} / \mathrm{min}$.

\subsection{Synthesis of FP}

FP was produced by reacting SO $(100 \mathrm{~g})$ with alcoholic $\mathrm{NaOH}(30 \%)$ in a $500 \mathrm{~mL}$ round bottom flask, which was refluxed at $80^{\circ} \mathrm{C}$ for $3 \mathrm{~h}$. Alcohol was distilled off and the soap formed was dissolved in hot deionized water. The solution formed was acidified with $\mathrm{H}_{2} \mathrm{SO}_{4}$, washed with deionized water and dried over anhydrous sodium sulphate. The product obtained was dissolved in phenylhydrazine $(120 \mathrm{~mL})$, allowed to boil for $20 \mathrm{~min}$, cooled and filtered under suction. The residue was washed in petroleum ether and later dissolved in methanol $(100 \mathrm{~mL})$ with the addition of potassium thiocyanate $(0.05 \mathrm{M})$ and $\mathrm{HCl}$ $(3 \mathrm{~mL})$ under continuous stirring at $60^{\circ} \mathrm{C}$ for $1 \mathrm{~h}$. The solvent was replaced with ethanol $(100 \mathrm{~mL})$ and refluxed for another $1 \mathrm{~h}$ at $80^{\circ} \mathrm{C}$ while water was added $(40 \mathrm{~mL})$. The final product obtained was dried overnight at room temperature. The steps involved in the synthesis is shown in Scheme 1.

\subsection{Characterization of SO and FP}

The functional groups in SO and FP were determined in the range of $400-4500 \mathrm{~cm}^{-1}$ using FTIR (FTIR, Perkin Elmer, spectrum RXI 83303, MA, USA) while the ${ }^{1} H N M R$ was carried out using a $400 \mathrm{MHz}$ Bruker NMR spectrophotometer in $\mathrm{CDCl}_{3}$ containing some amount of TMS as internal standard.

\subsection{Corrosion study}

\subsubsection{Weight loss}

The corrosion inhibition study of carbon steel was carried out using weight loss method [14]. The carbon steel sheets $(0.1 \mathrm{~mm}$ in thickness) used was purchased from a local market in Ibadan, Nigeria. The sheets were mechanically cut into $4 \times 4 \mathrm{~cm}$ coupons, degreased and dried in acetone. The coupons were pre-weighed and completely immersed in $100 \mathrm{~mL}$ test solutions without and with varying concentration of $\mathrm{FP}$; ranging from 0.5 to $1.0 \mathrm{mg} \mathrm{L}^{-1}$ in $0.5 \mathrm{M} \mathrm{HCl}$ for a period of $34 \mathrm{~h}$. During the study, coupons were retrieved from test solution at $10 \mathrm{~min}$ interval progressively for $34 \mathrm{~h}$, these were washed thoroughly in deionized water, dried in acetone, and re-weighed. The difference in the weight of the coupons before and after complete immersion in test solutions was recorded as weight loss. The experiment was repeated at different temperatures ranging from 303 to $323 \mathrm{~K}$ to evaluate the effect of temperature on the rate of corrosion and efficiency of FP. 


\section{REACTION SCHEME}

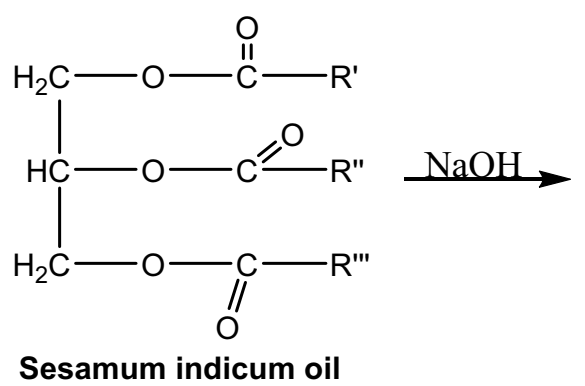<smiles>OCC(O)CO</smiles><smiles></smiles><smiles>[R]C(=O)NNC(=S)Nc1ccccc1</smiles><smiles>[R]C(=O)NNc1ccccc1</smiles><smiles>[R]C(=O)NNC(=S)Nc1ccccc1</smiles><smiles>[R]C(=O)NNc1ccccc1</smiles><smiles>NNc1ccccc1</smiles><smiles>[R]C(=O)NNC(=S)Nc1ccccc1</smiles><smiles>[R]C(=O)NNc1ccccc1</smiles>

Fatty phenylthiosemicarbazide

Scheme 1 Synthesis of FP

\subsubsection{Quantum chemical calculations}

All theoretical calculations were performed using the DFT electronic structure programs at B3LYP/6-31G level theory using Spartan 14.1 software.

\section{Results and discussion}

\subsection{Fatty acid composition, synthesis and characterization of SO and FP}

The fatty acid composition of SO is presented in Table 1. The values obtained for SO in this study is similar to previous report [15] but with slight difference which may

Table 1 Fatty acid composition of SO

\begin{tabular}{lc}
\hline Fatty acid & Composition (\%) \\
\hline C16:0 & 9.38 \\
C16:1 & 0.10 \\
C18:0 & 5.07 \\
C18:1 & 40.06 \\
C18:2 & 43.77 \\
C18:3 & 0.53 \\
C20:0 & 0.51 \\
C20:1 & 0.47 \\
C22:0 & 0.11 \\
Unsaturation & 84.93 \\
Saturation & 15.07 \\
\hline
\end{tabular}


be due to geographical difference in the source of the seed. The currently SO was grown in the Northern region of Nigeria unlike in the previous study [15], which was grown in Western region of Nigeria. The fatty acid composition revealed $\mathrm{C} 18: 2(43.77 \%)$ and $\mathrm{C} 18: 1(40.06 \%)$ as the major fatty acid composition of $\mathrm{SO}$. This also revealed the presence of $\mathrm{C} 20: 1(0.47 \%)$ and $\mathrm{C} 22: 0(0.11 \%)$ which were not detected in the previous study [15]. The unsaturated fatty acids were found to be $84.93 \%$ while saturation was $15.07 \%$. The result of the FTIR for SO and FP are presented in Fig. 1. Both SO and FP showed peaks at 3010, 2943 and $2852 \mathrm{~cm}^{-1}$, corresponding to the vibrational frequencies for unsaturation $(\mathrm{H}-\mathrm{C}=\mathrm{C}-\mathrm{H})$, methyl group $\left(-\mathrm{C}-\mathrm{CH}_{3}\right)$ and methylene group ( $-\mathrm{C}-\mathrm{CH}_{2}-\mathrm{C}-$ ) of alkane respectively. The vibrational frequency for ester carbonyl group was found in $\mathrm{SO}$ at $1742 \mathrm{~cm}^{-1}$. This peak had disappeared in FP suggesting conversion of $\mathrm{SO}$ (triglyceride) to FP. The $-\mathrm{C}-\mathrm{O}-\mathrm{C}$ stretching of ester group was only seen in $\mathrm{SO}$ at $1115 \mathrm{~cm}^{-1}$. The $\mathrm{C}-\mathrm{H}$ out of plane bending of alkane was seen at $984 \mathrm{~cm}^{-1}$ while the $\mathrm{C}=\mathrm{C}$ cis rocking was seen at $1119 \mathrm{~cm}^{-1}$. The $\mathrm{N}-\mathrm{H}$ vibrational frequency appeared at $3214 \mathrm{~cm}^{-1}$ while the peak for $\mathrm{N}-\mathrm{C}=\mathrm{O}$ was seen at $1661 \mathrm{~cm}^{-1}$ in FP. The aromatic stretching in $\mathrm{FP}$ appeared at $1505 \mathrm{~cm}^{-1}$ while the peak at $1065 \mathrm{~cm}^{-1}$ was assigned to the $-\mathrm{N}-\mathrm{N}-\mathrm{H}$ in FP. The peak at $855 \mathrm{~cm}^{-1}$ was attributed to $-\mathrm{H}-\mathrm{N}-\mathrm{C}=\mathrm{S}$ vibration which further suggests the formation of FP. The ${ }^{1} \mathrm{HNMR}$ signals are presented in Fig. 2 . The methyl protons were seen at $0.6-1.0 \mathrm{ppm}$ in $\mathrm{SO}$ and at around $1.8 \mathrm{ppm}$ in FP. The methylene protons appeared at $1.5 \mathrm{ppm}$ in SO where as it was seen at $2.1 \mathrm{ppm}$ in FP. The signal at $2.4 \mathrm{ppm}$ was attributed to the presence of allylic protons in $\mathrm{SO}$, similar signal seen at $2.5 \mathrm{ppm}$ in FP was also assigned to allylic protons. The unsaturation peak was seen at $5.2 \mathrm{ppm}$ in SO which appeared at $3.8 \mathrm{ppm}$ in FP, this peak confirms the peak seen in the FTIR at $3010 \mathrm{~cm}^{-1}$ in both $S O$ and FP. The signal at 3.2-3.4 ppm in SO was accounted for as being signal from the triglyceride backbone. This signal was not found in FP indicating the hydrolysis of the triglyceride bond during treatment with $\mathrm{NaOH}$ as shown in Scheme 1. The ester signal from the triglyceride seen in SO at $2.8 \mathrm{ppm}$ was not found in FP indicating the conversion of the triglyceride to phenylthiosemicarbazide. The signal from the FP at $2.5 \mathrm{ppm}$ was attributed to the $\mathrm{N}-\mathrm{H}$ signal while signal at $7.1 \mathrm{ppm}$ was associated with the aromatic ring protons. The $\mathrm{H}-\mathrm{N}-\mathrm{C}=\mathrm{O}$ protons appeared at $9.2 \mathrm{ppm}$ while the $\mathrm{Ar}-\mathrm{N}-\mathrm{H}$ proton was seen at $9.5 \mathrm{ppm}$. The peak at $6.9 \mathrm{ppm}$ in $\mathrm{FP}$ and $7.3 \mathrm{ppm}$ in SO were both attributed to the solvent peak.

\subsection{Corrosion study}

\subsubsection{Weight loss}

The weight loss method was applied in evaluating the surface wear-off during the corrosion of the carbon steel. The result is shown in Fig. 3a. The weight loss reduced as concentration of FP increased from 0.5 to $1.0 \mathrm{mg} \mathrm{L}^{-1}$. The highest loss was found in the blank, which did not contain FP.
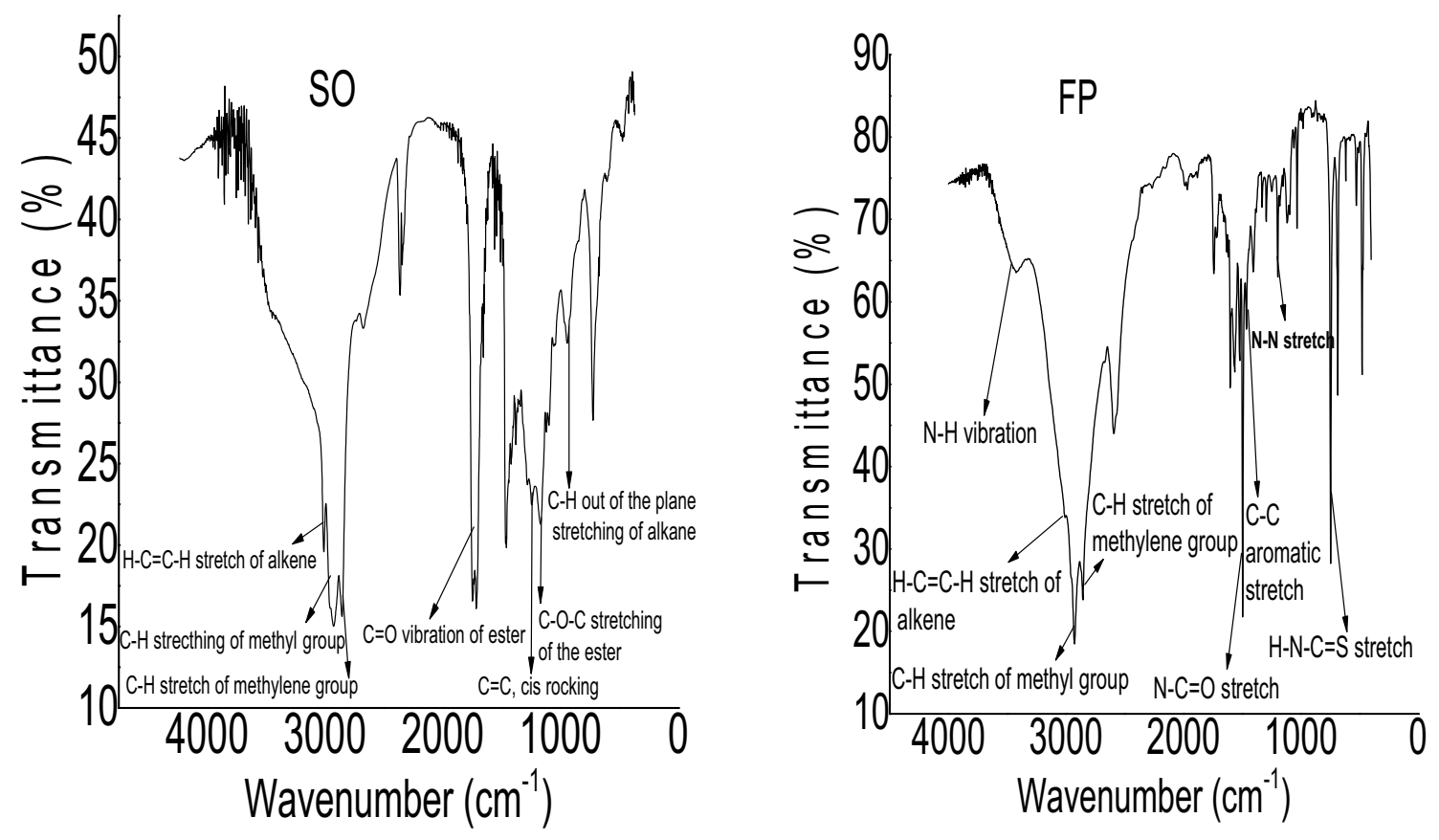

Fig. 1 FTIR of SO and FP

SN Applied Sciences

A SPRINGER NATURE journal 

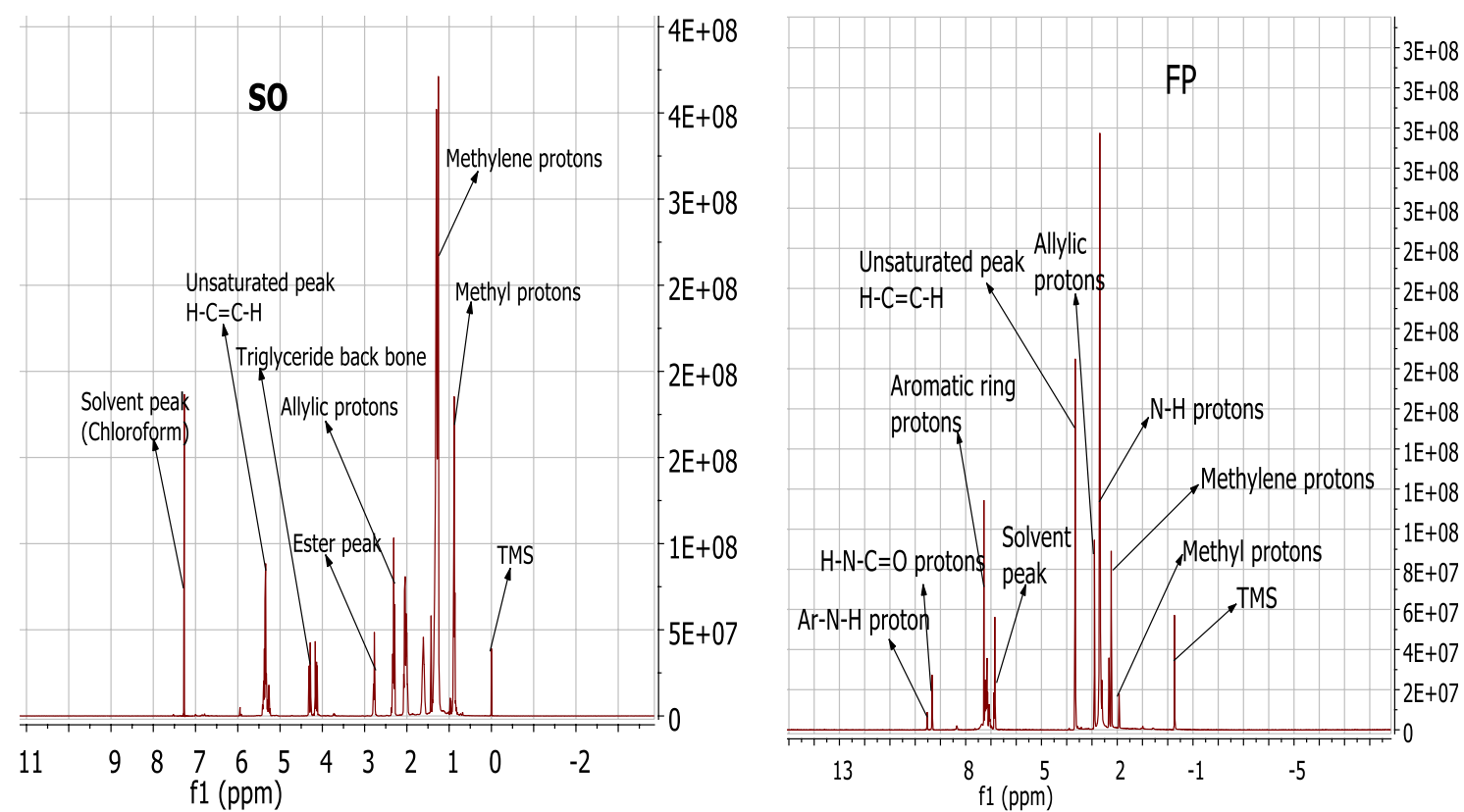

Fig. $2{ }^{1} \mathrm{HNMR}$ of SO and FP
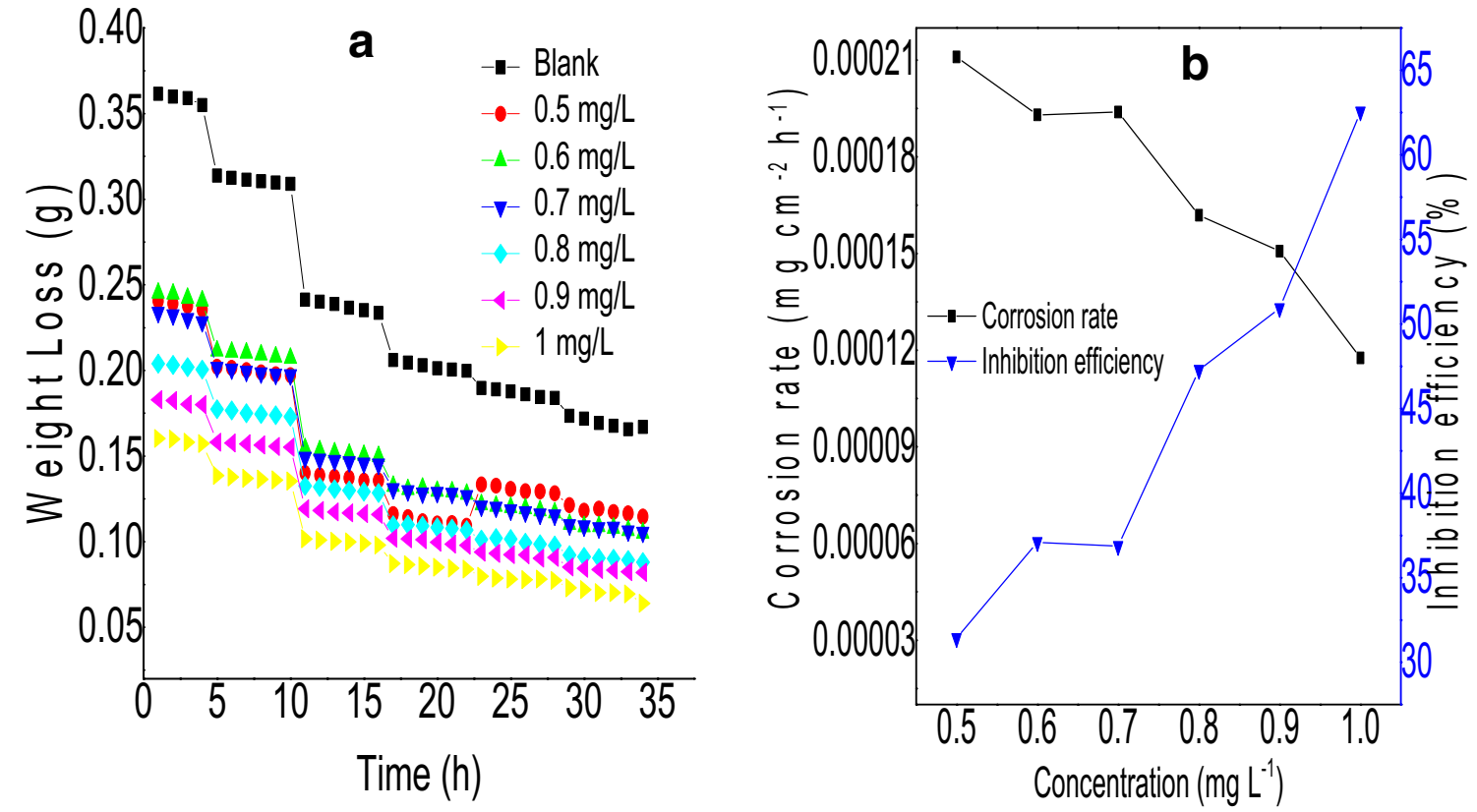

Fig. 3 a Steel weight lose without and with FP at different concentrations, b variation of corrosion rate and inhibition efficiency of steel in the presence of FP at room temperature

The loss also reduced with time, which might be due to the reduction in hydrogen ion concentration due to the reaction shown below which may be considered as being a cathodic and anodic reaction:

$\mathrm{Fe} \rightarrow \mathrm{Fe}^{2+}+e^{2-}$
$2 \mathrm{H}^{+}+2 \mathrm{e}^{2-} \rightarrow 2 \mathrm{H}_{\text {ads }} \rightarrow \mathrm{H}_{2}$

The corrosion rate and efficiency of FP at different concentrations of FP was checked at room temperature, this is presented in Fig. $3 \mathrm{~b}$. The corrosion rate was calculated as shown below: 
$R=\frac{\Delta W}{N t}$

$R\left(\mathrm{mg} \mathrm{cm}^{-2} \mathrm{~h}^{-1}\right)$ is the corrosion rate, $N\left(\mathrm{~cm}^{2}\right)$ is the surface area of the coupon, $t$ represents time (h) of immersion while $\Delta W$ is the average weight loss after immersion. The corrosion inhibition efficiency (\%l) of FP was calculated as shown below using the corrosion rate:

$\% I=\left(1-\frac{R_{t}}{R_{o}}\right) \times 100$

$R_{o}$ and $R_{t}$ are corrosion rates of carbon steel sheet without and with FP, respectively. The corrosion rate decrease with increase in concentration of FP while the efficiency increased with increase in concentration of FP. The ability of FP to inhibit corrosion of carbon steel may be due to the interaction between the surface of the carbon steel and the electron density of the molecule of FP [16]. The structure of FP (Scheme 1) reveals the presence of heteroatoms such as sulphur, nitrogen and oxygen as well as the pie $(\pi)$ electron system of the benzene ring. The nonbonding electrons from the heteroatoms and the $\pi$ electrons may have created the electron density involved in the interaction between the carbon steel surface and FP. The increase in the concentration of FP must have made available more molecules of $\mathrm{FP}$, which may have increased the electron density and as such better interaction with the carbon steel surface. This increase in concentration may have also decreased the anodic and cathodic polarization at the surface of the carbon steel. The highest inhibition efficiency was found to be $62.55 \%$ at a test concentration of $1.0 \mathrm{mg} \mathrm{L}^{-1}$.

\subsubsection{Adsorption isotherm}

Data obtained were ran for some adsorption isotherms which included; Temkin, Freundlich, Frumkin and Langmuir. However, the data fitted best for Langmuir. This was achieved by subjecting data obtained to:

$\frac{C}{\theta}=\frac{1}{K_{a d s}}+C$

$C$ is concentration of $\mathrm{FP}, \theta$ is the surface coverage while $K_{\text {ads }}$ represents the equilibrium constant for FP carbon steel corrosion inhibition process. However, surface coverage $(\theta)$ was calculated as:

$\theta=\left(R_{o}-\frac{R_{t}}{R_{o}}\right)$

where $R_{t}$ and $R_{o}$ are corrosion rates of steel with and without $F$, respectively. The plot of $C / \theta$ versus $C$ is presented in Fig. 4, which gave a straight line with an $r^{2}$ value of 0.966 .

The fit of this plot suggest a monolayer covering of the

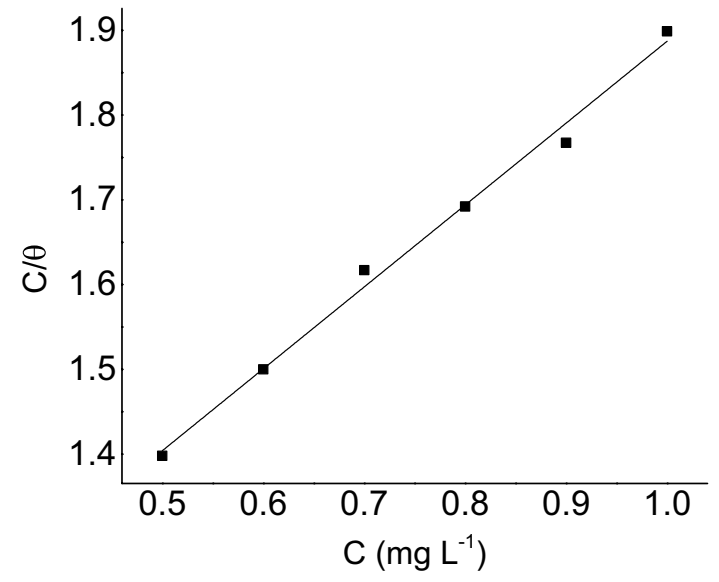

Fig. 4 Langmuir isotherm plots for FP adsorption on carbon steel corrosion in $0.5 \mathrm{M} \mathrm{HCl}$

Table 2 Interpretation of $K_{N}$ parameter

\begin{tabular}{ll}
\hline Values of $K_{N}$ & Type of isotherm \\
\hline$K_{N}>1$ & Unfavorable \\
$K_{N}=1$ & Linear \\
$0<K_{N}<1$ & Favorable \\
$K_{N}=0$ & Irreversible \\
\hline
\end{tabular}

surface of the carbon steel by FP [17]. Langmuir isotherm essential characteristic was calculated as:

$K_{N}=\frac{1}{1+K_{a d s} C}$

$K_{N}$ is the equilibrium parameter, $C$ is the concentrate of FP and $K_{\text {ads }}$ represents Langmuir constant. $K_{N}$ is characteristic of Langmuir isotherm and it is capable of suggesting the shape of the isotherm. The interpretation of this is presented in Table 2. For the inhibition of carbon steel corrosion by FP, $K_{N}$ was found to be $0.9157\left(0<K_{N}<1\right)$. This suggests that Langmuir isotherm was favoured during the inhibition of corrosion in carbon steel by FP. Other previous studies have also shown that corrosion inhibition on metal is favoured by Langmuir isotherm [18-20]. The $\Delta G_{a d s}^{\circ}$ for the process was also calculated as:

$\Delta G_{\text {ads }}=-2.303 R T \log \left(55.5 K_{\text {ads }}\right)$

$R$ is the gas constant, $T$ is the absolute temperature, $K_{\text {ads }}$ is the equilibrium constant for the adsorption of $\mathrm{FP}$ on carbon steel and the constant 55.5 is the molar concentration of water solution in $\mathrm{mol} \mathrm{L}^{-1}$. The values obtained for $\Delta G_{a d s}^{\circ}$ was plotted against corrosion inhibition rate at different temperature as presented in Fig. $5 a$. The values $\Delta G_{a d s}^{\circ}$ decreased with increase in temperature whereas that of corrosion inhibition rate increased with increased in temperature. The negative value of $\Delta G_{\text {ads }}^{\circ}$ suggests the 

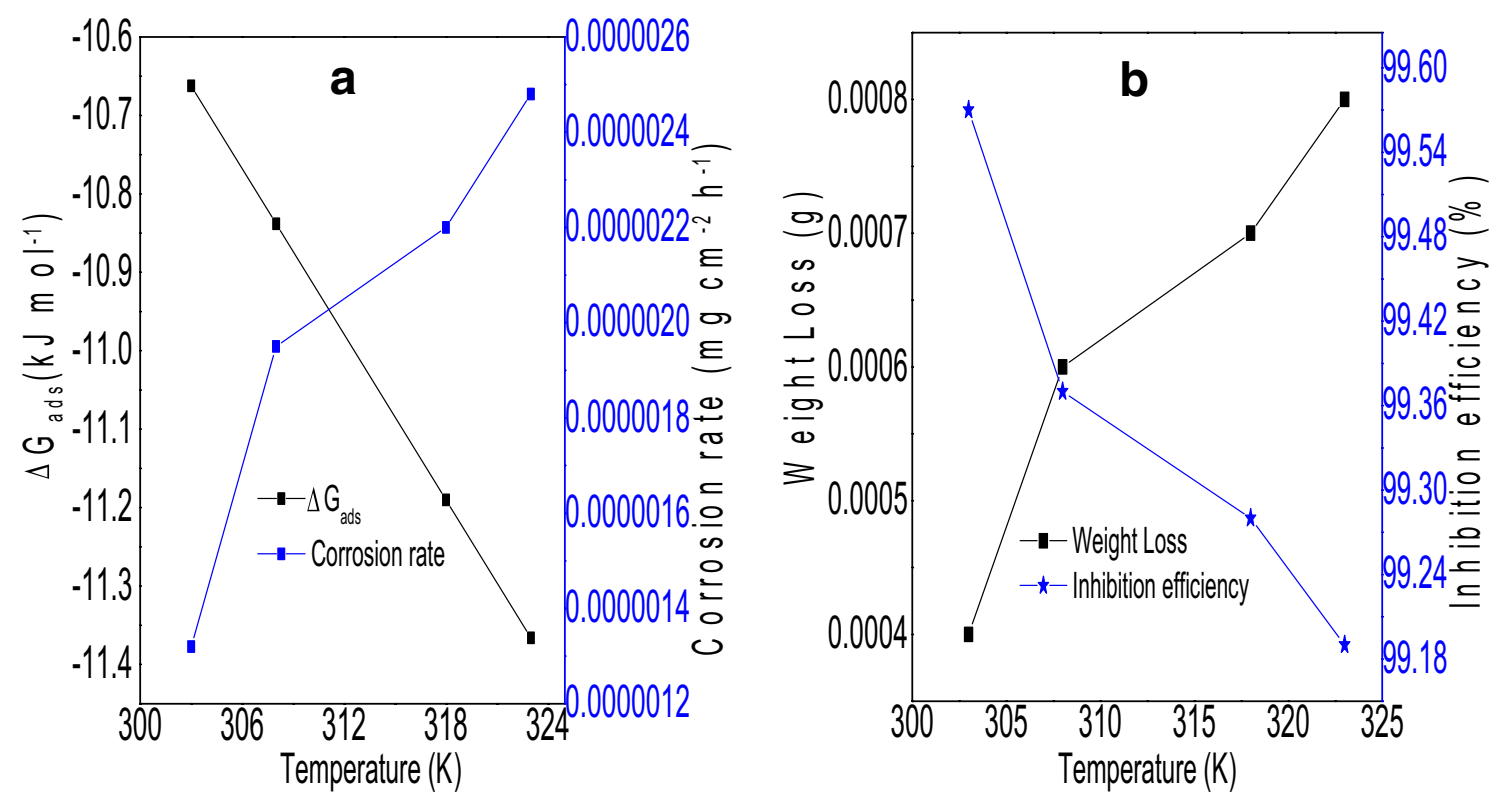

Fig. 5 a Relationship between $\Delta G_{a d s}^{\circ}$ and corrosion inhibition of steel at the different temperature, b weight loss Vs inhibition efficiency at different temperature range

corrosion inhibition process of FP to be spontaneous. The values ranged from -10.6623 to $-11.3660 \mathrm{~kJ} \mathrm{~mol}^{-1}$. The values obtained are less than $40 \mathrm{~kJ} \mathrm{~mol}^{-1}$ which indicates that the process is physisorption as previous studies have shown values of $\Delta G_{\text {ads }}^{\circ}<40 \mathrm{~kJ} \mathrm{~mol}^{-1}$ connotes physisorption while values above it suggests chemisorption [21, 22].

\subsubsection{Effect of temperature}

The effect of temperature on the capacity of FP as a corrosion inhibitor of carbon steel was studied at a range of 303-323 K. The effect of temperature on the performance of FP towards weight loss was compared with efficiency as presented in Fig. 5b. It was observed that weight loss increased with increase in temperature while the efficiency decrease with increase in temperature. The increase in weight loss as temperature increased may be due to the increase in corrosion reaction at the surface of the carbon steel as the average kinetic energy of reacting species increases with increasing temperature. The observed reduction in efficiency of FP as temperature increases may be due to the inability of FP to catch up with the increased corrosion reaction at the surface of the carbon steel. Moreover, $\Delta G_{a d s}^{\circ}$ value revealed that the corrosion process is spontaneous and the inhibition decreased with increase temperature in a reaction that is physisorption. Since the process is physisorption, the bonding of FP to the surface of carbon steel may have become weak, as the temperature increases resulting in increase in dissolution of hydrogen gas generated during this process. The increase in hydrogen gas generation may have agitated the carbon steel/FP interface and could have hindered FP adsorption or perturbed the already adsorbed FP on the surface of carbon steel [23].

Arrhenius equation was applied to express the relationship between corrosion rate and temperature, which is expressed as:

$\log \frac{\rho_{2}}{\rho_{1}}=\frac{E_{a}}{2.303 R}\left(\frac{1}{T_{1}}-\frac{1}{T_{2}}\right)$

$\rho_{1}$ and $\rho_{2}$ represents the corrosion rates at temperature $\mathrm{T}_{1}(303 \mathrm{~K})$ and $\mathrm{T}_{2}(323 \mathrm{~K}), \mathrm{R}$ is the molar gas constant and $E_{a}$ is the activation energy. $E_{a}$, which describes the energy barrier that must be overcome for the inhibition of corrosion in carbon steel by FP was found to be $25.606 \mathrm{~kJ} \mathrm{~mol}^{-1}$.

Values for $\Delta H_{a d s}^{\circ}$ and $\Delta S_{a d s}^{\circ}$ were obtained from the expression:

$\Delta G_{a d s}^{\circ}=\Delta H_{a d s}^{\circ}-T \Delta S_{a d s}^{\circ}$

$\Delta H_{\text {ads }}^{\circ}$ is the enthalpy, $T$ is the temperature, $\Delta G_{\text {ads }}^{\circ}$ is the standard free energy and $\Delta S_{\text {ads }}^{\circ}$ is the entropy. The values of $\Delta H_{\text {ads }}^{\circ}$ and $\Delta S_{\text {ads }}^{\circ}$ for the corrosion inhibition process was obtained from the slope $\left(\Delta H_{\text {ads }}^{\circ} / R\right)$ and intercept $\left(\Delta S_{\text {ads }}^{\circ}\right.$ $/ R-\ln 55.5)$ of van't Hoff plots. This was from the plot of In $K$ against $1 / T$. Value of for $\Delta H_{\text {ads }}^{\circ}$ was $-1.088 \mathrm{~kJ} \mathrm{~mol}^{-1}$ which is indicative of an exothermic process while $\Delta S^{\circ}$ was $-0.015 \mathrm{~kJ} \mathrm{~mol}^{-1} \mathrm{~K}^{-1}$ suggesting an increased entropy for the sorption of FP on the surface of carbon steel, which is the driving force for the process. 


\subsubsection{Quantum chemical computations}

The quantum computation of FP is useful in understanding its molecule at subatomic level in order to describe the corrosion inhibition of FP in carbon steel under acidic medium [24]. The computation was achieved using DFT at B3LYP/6-31G level theory using Spartan 14.1 software which was helpful in providing theoretical basis in describing the contributions of FP towards the exhibited corrosion inhibition at the surface of the studied carbon steel. The reactivity of FP at the inhibition sites on the carbon steel was further examined via geometry optimization. This was achieved by modelling the molecular electronic structure and the distribution of the frontier molecular orbitals of the constituents of FP. Based on the fatty acid composition as shown in Table 1, the saturated fatty phenylthiosemicarbazide present in FP are presented in Fig. 6 while the unsaturated fatty phenylthiosemicarbazide present in it are shown in Fig. 7. The HOMO and LUMO density distribution of FP for saturated fatty phenylthiosemicarbazide and unsaturated fatty phenylthiosemicarbazide are presented in Figs. 8 and 9; respectively. The presence of the heteroatoms introduced negative charges in the system of FP. These atoms, nitrogen, oxygen and sulphur are capable of donating electrons to the unoccupied orbitals of the carbon steel. The Mulliken atomic charges described from the computation revealed the molecules of FP to possess atoms capable of donating electrons to the orbital of the carbon steel for bonding. This observed

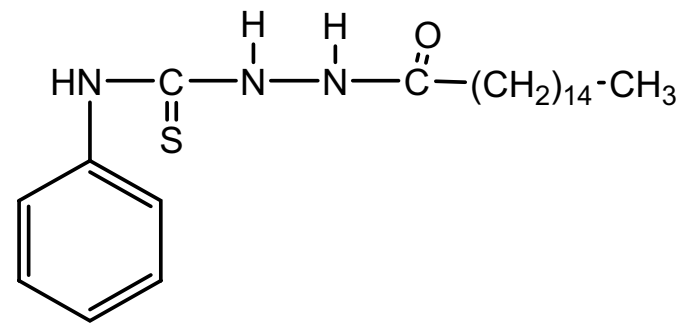

C16:0-phenylthiosemicarbazide (I)

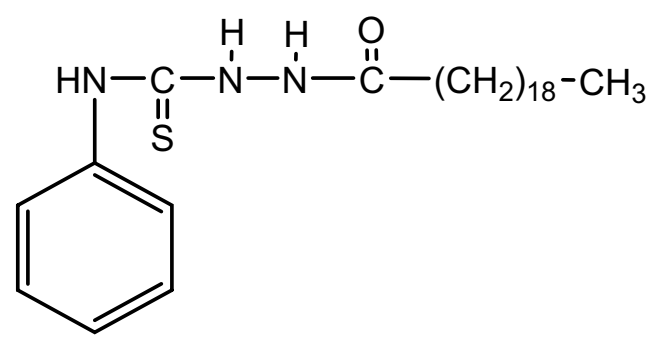

C20:0-phenylthiosemicarbazide (III) capacity may have resulted in the interaction between the surface of the carbon steel and FP.

Due to the presence of lone pairs of electrons in sulphur, nitrogen and oxygen as well as the $\pi$-electrons in FP, both the HOMO and LUMO are distributed over the molecules of the saturated and unsaturated fatty phenylthiosemicarbazides, which are the constituents of FP. As previously reported $[25,26]$, region of the molecule with highest electron density (HOMO) are the sites at which, electrophiles attack and represents the active centers. This represents the utmost energy to bond to the surface of carbon steel whereas the LUMO orbital of FP accepts electrons from the orbital of carbon steel using antibonding orbitals to form feedback bonds. This interaction between the molecules of FP and carbon steel results in the formation of adsorption centers which are capable of forming flat orientation of FP molecules on the surface of the carbon steel giving rise to surface coverage and inhibition exhibited by FP. Since the heteroatoms contain nonbonding electrons, they are most likely the reactive site for the adsorption of FP on the surface of carbon steel which suggests the inhibition of corrosion exhibited by FP in the carbon steel to have taken place via donor-acceptor interaction among the nonbonding electrons, $\pi$-electrons and the vacant $\mathrm{d}$-orbital of carbon steel [27]. The calculated quantum chemical properties for the saturated and unsaturated fatty constituents of FP are presented in Tables 3 and 4; respectively. The tables revealed higher LUMO energy, which suggests high electron donating capacity to low energy empty molecular orbital of carbon steel. Since the

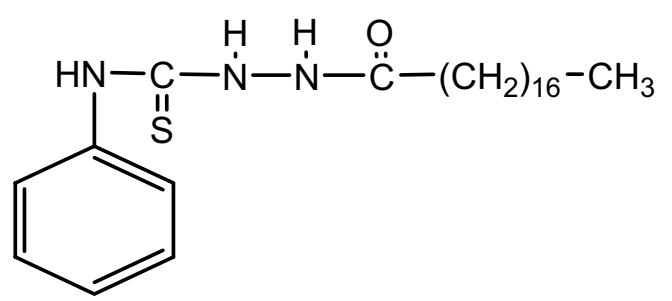

C18:0-phenylthiosemicarbazide (II)<smiles>CCCCCCCCCCCCCCCCCCCCCNC(=S)Nc1ccccc1</smiles>

C22:0-phenylthiosemicarbazide (IV)

Fig. 6 Saturated fatty phenylthiosemicarbazide present in FP 


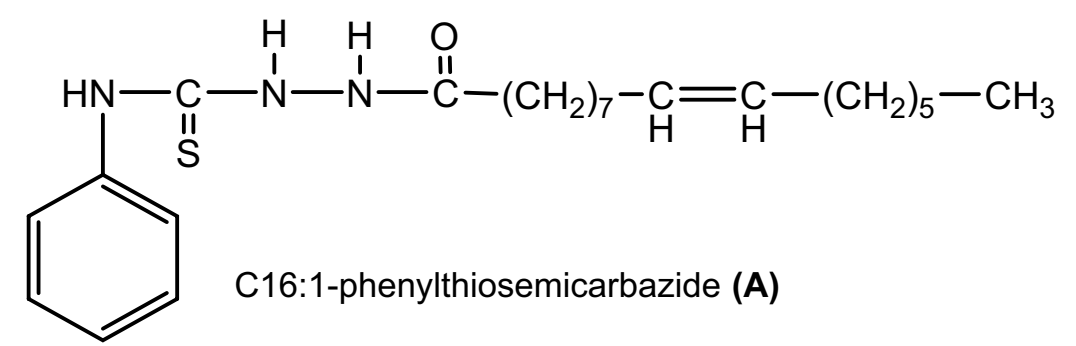<smiles>C[In]CC=CCCCC(=O)NNC(=S)Nc1ccccc1</smiles>

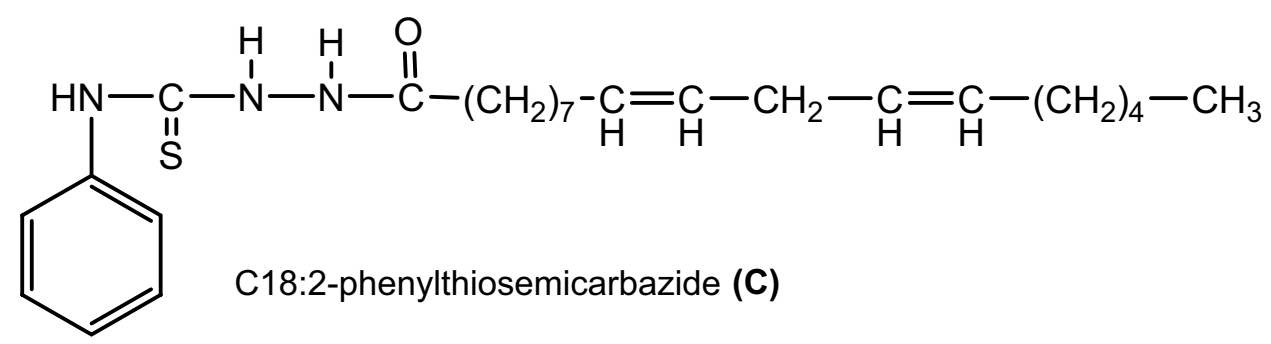

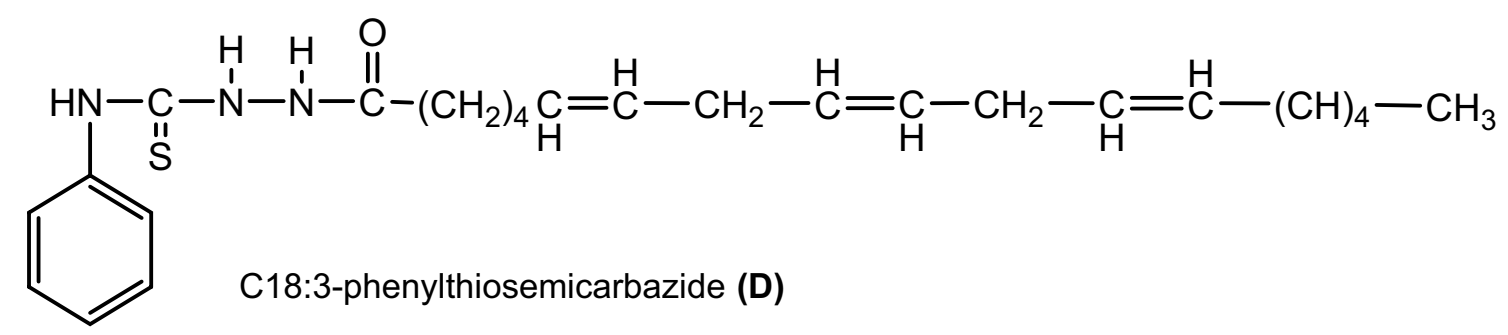

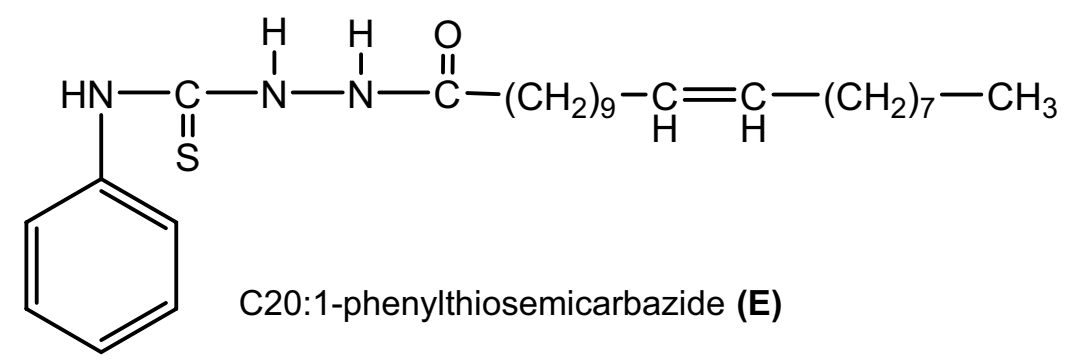

Fig. 7 Unsaturated fatty phenylthiosemicarbazide present in FP

electronic configuration of Fe is $1 s^{2} 2 s^{2} 2 p^{6} 3 s^{2} 3 p^{6} 3 d^{6} 4 s^{2}$, then the incompletely filled $3 d$ orbital can bond with the HOMO of FP while the LUMO interact with the $4 s$ orbital.
The molecular surface area, volume and polarizability of the constituent saturated and unsaturated fatty phenylthiosemicarbazides increased as the carbon chain length 

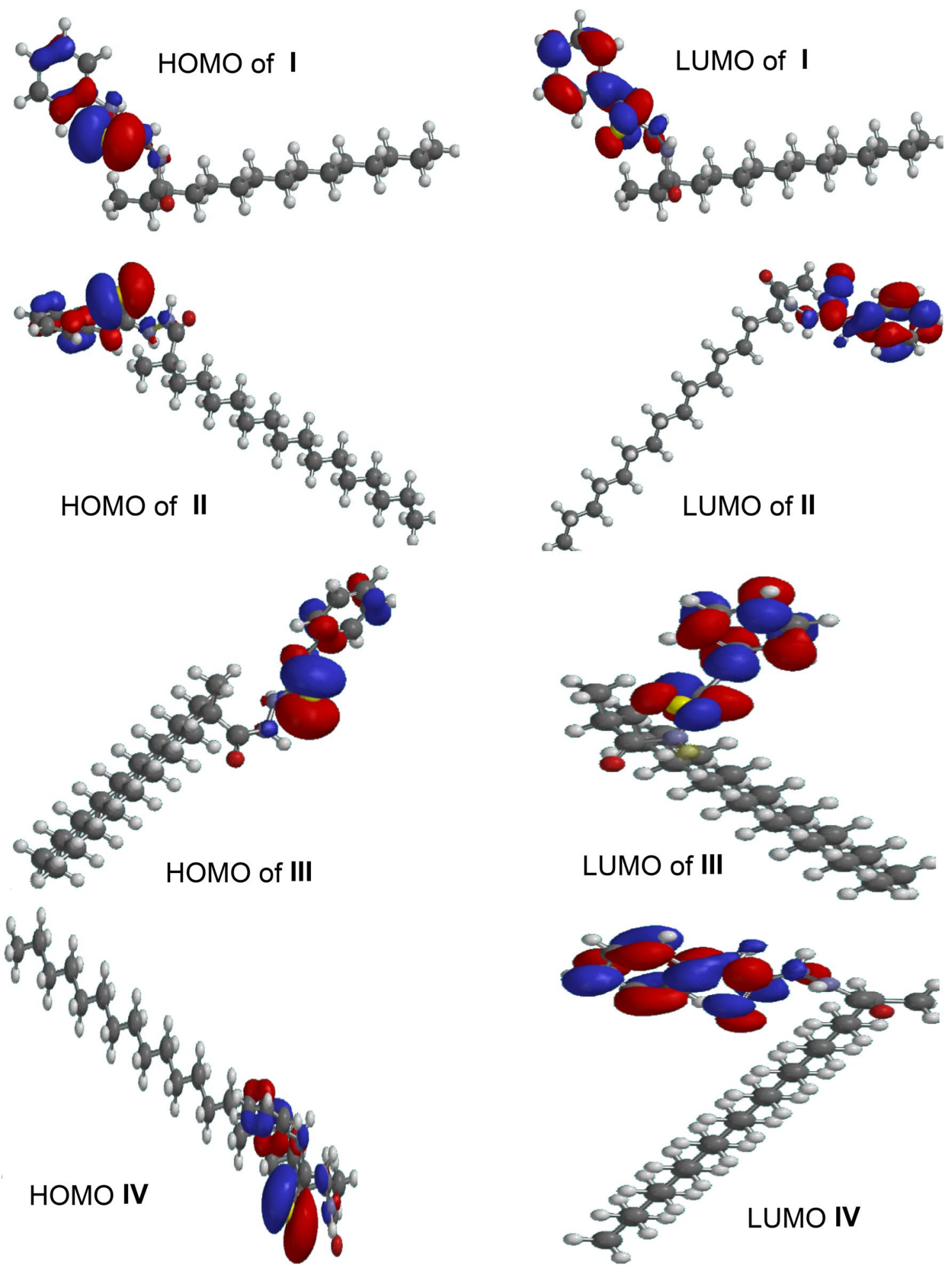

Fig. 8 HOMO and LUMO density distribution of saturated fatty phenylthiosemicarbazides in FP

increased from $\mathrm{C} 16$ to $\mathrm{C} 22$. These values are higher in the saturated constituents than values obtained for the unsaturated fatty phenylthiosemicarbazides constituents of FP. This suggests the important role the unsaturated fatty moiety played in achieving the adsorption on the surface of the carbon steel. These values reduced as the number of double bonds ( $\pi$ electron system) increased in the C18 fatty moiety. This further corroborate the fact that the interaction 

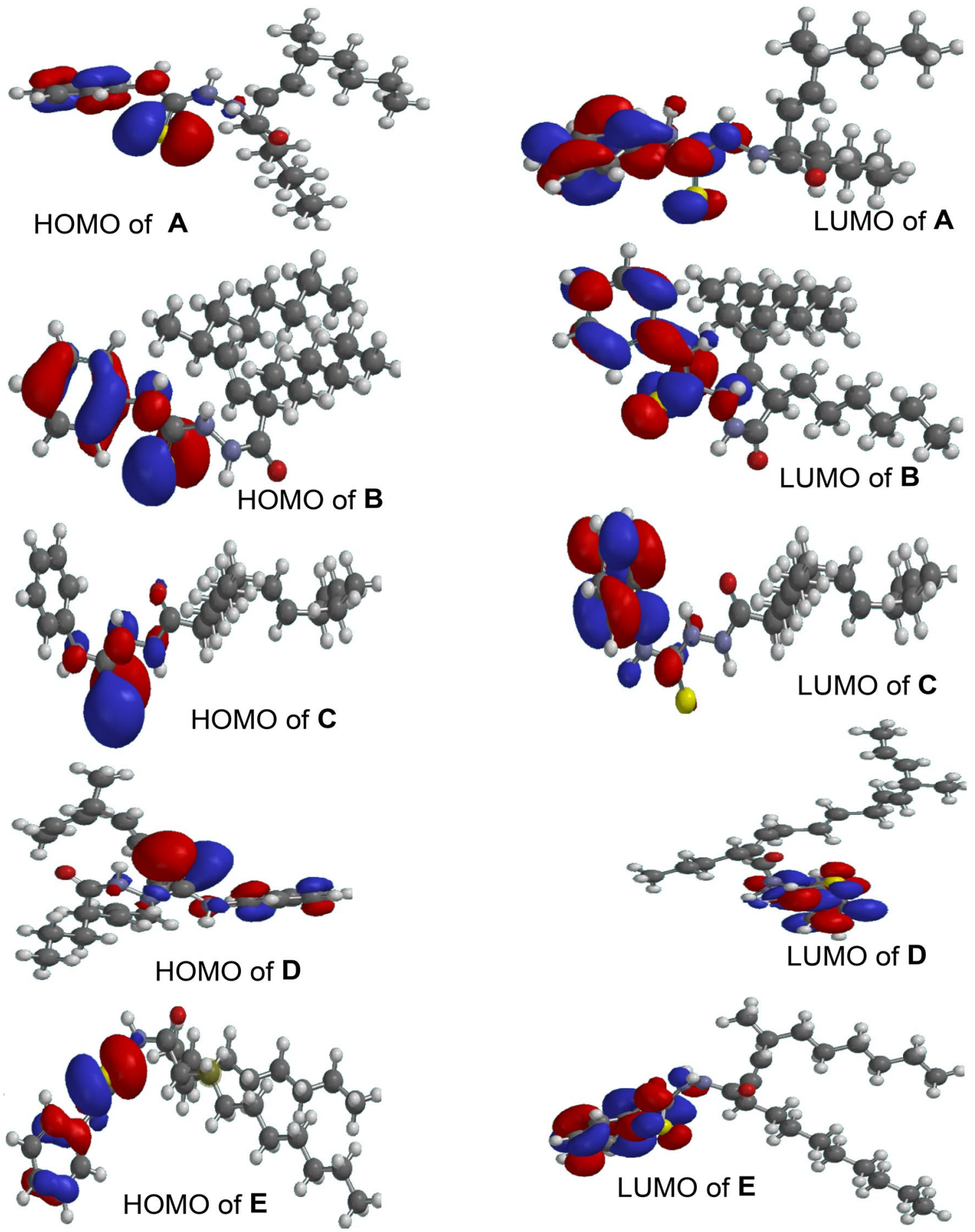

Fig. 9 HOMO and LUMO density distribution of unsaturated fatty phenylthiosemicarbazides in FP

between FP and the surface of carbon steel is driven by the donation of electron to the vacant $d$-orbital of carbon; a process which is promoted as the number of $\pi$ electron sources increased in the C18 fatty moiety from C18:1 to C18:3 (molecules B, C and D). Values obtained for the dipole moment was lower in the unsaturated fatty phenylthiosemicarbazides than the saturated fatty phenylthiosemicarbazides which might be due to the higher electron density that exist in the unsaturated fatty phenylthiosemicarbazides molecules, however, among the unsaturated fatty phenylthiosemicarbazides, molecule $\mathrm{C}$ with two double bonds in the linear alkyl chain has the lowest $\mathrm{E}_{\mathrm{LUMO}}$ value $(3.19 \mathrm{eV})$. This showed 
Table 3 Calculated quantum chemical properties for the saturated fatty constituents of FP

\begin{tabular}{lccrc}
\hline Quantum chemical property & \multicolumn{1}{l}{ I } & III & IV \\
\hline Molecular surface area $\left(\AA^{2}\right)$ & 511.04 & 551.36 & 591.67 & 637.04 \\
Energy $(\mathrm{au})$ & -1521.285 & -1598.923 & -1676.561 & -1754.221 \\
Solvation energy $\left(\mathrm{kJ} \mathrm{mol}^{-1}\right)$ & -46.03 & -44.65 & -43.21 & -43.12 \\
$\mathrm{E}_{\text {HOMO }}(\mathrm{eV})$ & -8.62 & -8.62 & -8.62 & -8.64 \\
$\mathrm{E}_{\text {LUMO }}(\mathrm{eV})$ & 3.29 & 3.29 & 3.29 & 3.28 \\
$\mathrm{E}_{\text {LUMO-HOMO }}(\mathrm{eV})$ & 11.91 & 11.91 & 11.91 & 11.92 \\
Dipole moment (debye) & 7.51 & 7.51 & 7.51 & 7.32 \\
Volume $\left(\AA^{3}\right)$ & 461.45 & 498.23 & 535.00 & 572.14 \\
Polarizability & 76.01 & 78.99 & 81.98 & 84.98 \\
$\eta(\mathrm{eV})$ & 5.96 & 5.96 & 5.96 & 5.96 \\
\hline
\end{tabular}

Table 4 Calculated quantum chemical properties for the unsaturated fatty constituents of FP

\begin{tabular}{lrrrrr}
\hline Quantum chemical property & \multicolumn{1}{c}{$\mathrm{A}$} & $\mathrm{B}$ & $\mathrm{C}$ & $\mathrm{D}$ & $\mathrm{E}$ \\
\hline Molecular surface area $\left(\AA^{2}\right)$ & 503.33 & 541.10 & 536.89 & 528.42 & 584.05 \\
Energy $(\mathrm{au})$ & -1520.11 & -1597.74 & -1596.57 & -1594.18 & -1675.39 \\
Solvation energy $\left(\mathrm{kJ} \mathrm{mol}^{-1}\right)$ & -44.09 & -37.88 & -34.00 & -44.40 & -41.61 \\
$\mathrm{E}_{\text {HOMO }}(\mathrm{eV})$ & -8.53 & -8.55 & -8.47 & -8.63 & -8.52 \\
$\mathrm{E}_{\text {LUMO }}(\mathrm{eV})$ & 3.30 & 3.01 & 3.22 & 3.30 & 3.31 \\
$\mathrm{E}_{\text {LUMO-HOMO }}(\mathrm{eV})$ & 11.83 & 11.56 & 11.69 & 11.93 & 11.83 \\
Dipole moment (debye) & 7.34 & 7.14 & 3.19 & 7.00 & 7.33 \\
Volume $\left(\AA^{3}\right)$ & 456.06 & 492.93 & 487.96 & 480.19 & 529.62 \\
Polarizability & 75.59 & 78.64 & 78.21 & 77.52 & 81.56 \\
$\eta(\mathrm{eV})$ & 5.92 & 5.78 & 5.85 & 5.97 & 5.92 \\
\hline
\end{tabular}

that C18:2 played a significant role in the corrosion inhibition activity exhibited by FP being the most dominant fatty acid sourced phenylthiosemicarbazide molecule (43.77\%) in FP. This observed reduction in $\mathrm{E}_{\mathrm{LUMO}}$ in molecule $\mathrm{C}$ may be attributed to the increased electron density from the $\pi$ electron system. Although similar effect may have been expected in molecule D with three double bonds (C18:3) but its concentration $(0.53 \%)$ as fatty acid source is small compared to other fatty constituents belonging to the same carbon chain moiety (C18:1 and C18:2). Energy gap $(\Delta E)$ for both saturated and unsaturated fatty phenylthiosemicarbazides was calculated as:

$\Delta E=E_{\text {LUMO }}-E_{\text {HOMO }}$

Values obtained are higher in unsaturated fatty phenylthiosemicarbazides than the saturated constituents are. The value is an expression of the electronic interaction between the surface of the carbon steel and FP. It is the energy required to promote valence electron resulting in the surface interaction. The absolute hardness $(\eta)$ for the interaction was also calculated as:

$\eta=\frac{E_{L U M O}-E_{\text {HOMO }}}{2}$
The value of $\eta$ helps in determining the magnitude of the total electron transfer within the molecules of FP. This value is the same for all the examined saturated fatty phenylthiosemicarbazides whereas for the unsaturated fatty phenylthiosemicarbazides, the values obtained were lower in the $\mathrm{C} 18$ alkyl chains than other unsaturated molecules.

The corrosion inhibition exhibited by FP on carbon steel was compared with other corrosion inhibitor of carbon steel found in literature as presented in Table 5 . The corrosion inhibition exhibited by most of the inhibitor was higher than 70\% except for benzimidazole ligands [42]. FP compared favourably with all the inhibitor selected from literature. The highest inhibition (99.57\%) exhibited by FP is higher than those exhibited by most of the other good inhibitors reported except for APS- 16 which slightly exhibited a higher corrosion inhibition (99.60\%). Most inhibitors selected in literature showed positive enthalpy of reaction except for thiadiazole (SB 2) which exhibited a negative enthalpy of reaction like FP. This is an indication that most of these inhibitors exhibits their inhibition via endothermic reactions whereas FP and thiadiazole (SB 2) are exothermic in nature. The value of the $\Delta \mathrm{H}, \Delta \mathrm{S}$ and $\Delta G$ obtained for FP is lower than all other selected inhibitors in literature. The activation energy required for the corrosion inhibition by FP is positive just like for other 
Table 5 Comparison of the corrosion inhibition of FP on carbon steel with other inhibitors of carbon steel corrosion in literature

\begin{tabular}{|c|c|c|c|c|c|c|c|c|}
\hline Inhibitor & Efficiency (\%) & $\Delta \mathrm{H}\left(\mathrm{kJ} \mathrm{mol}{ }^{-1}\right)$ & $\begin{array}{l}\Delta \mathrm{S}(\mathrm{kJ} \mathrm{mol} \\
\left.\mathrm{K}^{-1}\right)\end{array}$ & $\Delta \mathrm{G}\left(\mathrm{kJ} \mathrm{mol}{ }^{-1}\right)$ & $\mathrm{Ea}\left(\mathrm{kJ} \mathrm{mol}{ }^{-1}\right)$ & $\begin{array}{l}\text { Adsorption } \\
\text { isotherm }\end{array}$ & Mechanism & References \\
\hline $\begin{array}{c}\text { Fig leaves } \\
\text { extract }\end{array}$ & 89.20 & - & - & -20.80 & 77.81 & Langmuir & Physisorption & {$[28]$} \\
\hline $\begin{array}{l}\text { Isatin deriva- } \\
\text { tives (TZ-2) }\end{array}$ & 99.30 & - & - & -32.85 & 192.82 & Langmuir & Physisorption & [29] \\
\hline APS-16 & 99.60 & 142.75 & -251.36 & -49.40 & 10.05 & Langmuir & - & {$[30]$} \\
\hline PQA & 95.18 & 66.36 & -21.80 & -36.00 & 69.00 & Langmuir & - & {$[31]$} \\
\hline $\begin{array}{l}\text { Thiadiazole } \\
\text { (SB 2) }\end{array}$ & 97.76 & -51.99 & -0.99 & -22.74 & 69.62 & Langmuir & - & [32] \\
\hline Tagetes erecta & 96.30 & 179.76 & -375.99 & -24.36 & 182.40 & Langmuir & - & [33] \\
\hline EBIMOT & 95.10 & 100.78 & 39.46 & -33.62 & 103.34 & Langmuir & - & [34] \\
\hline $\begin{array}{l}\text { Azadirachta } \\
\text { indica gum }\end{array}$ & 73.20 & - & - & - & - & - & - & {$[35]$} \\
\hline TMBHC & 94.80 & 24.11 & -162.20 & -43.61 & 26.75 & Langmuir & - & [36] \\
\hline Atenolol drug & 92.80 & - & - & -18.65 & - & Langmuir & - & [37] \\
\hline PVAC & 95.39 & 45.09 & -73.00 & 25.08 & 48.42 & El-Awady & - & [38] \\
\hline $\begin{array}{l}\text { Surfactants } \\
(\mathrm{Ag}-\mathrm{C} 16)\end{array}$ & 94.37 & 26.88 & -180.82 & - & 29.53 & - & Chemisorption & [39] \\
\hline Telmisartan & 97.39 & - & - & 34.28 & 95.64 & Temkin & Chemisorption & {$[40]$} \\
\hline BPMMP & 81.00 & - & - & -37.93 & - & Langmuir & Chemisorption & [41] \\
\hline $\begin{array}{l}\text { Benzimidazole } \\
\text { ligands }\end{array}$ & 69.22 & - & - & -32.96 & - & Langmuir & Chemisorption & {$[42]$} \\
\hline BBED & 89.00 & & & -45.80 & & Langmuir & Chemisorption & [43] \\
\hline $\begin{array}{l}\text { Theobroma } \\
\text { cacao peel }\end{array}$ & 96.03 & 196.14 & - & - & 198.80 & Langmuir & Chemisorption & [44] \\
\hline FP & 99.57 & -1.09 & -0.02 & -11.37 & 25.61 & Langmuir & Physisorption & This study \\
\hline
\end{tabular}

-, Not reported; APS-16, N,N-dimethyl-4-(((1-methyl-2-phenyl-2,3-dihydro-1H-pyrazol-4-yl)imino)methyl)- $N$-hexadecylbenzenaminium bromide; $P Q A, \quad N^{\prime}$-[(1Z)-phenylmethylene]-2-(quinolin-8-yloxy) acetohydrazide; EBIMOT, 5-((2-ethyl-1H-benzo[d]imidazol-1-yl)methyl)-1,3,4oxadiazole-2-thiol; TMBHC, 3,4,5-trimethoxybenzylidene)hydrazinecarbothioamide; PVAC, Poly(vinyl alcohol-cysteine); BPMMP, 2,6-bis[((2pyridylmethyl)oxy)methyl)]pyridine; $B B E D, N, N$-bis(benzimidazole-2-ylethyl)-1,2-diaminoethane

inhibitors previously reported in literature. However, the value is lower for FP when compared with other inhibitors suggesting the ease of the inhibition process by FP. The adsorption isotherm was found to be Langmuir just like in other inhibitors except for PVAC, which was reported as El-Awady [38] and Telmisartan, which was reported as Temkin [40]. The mechanism of reaction vary for most reported inhibitors when compared among themselves. The mechanism was reported to be either chemisorption or physisorption. For most reported inhibitors, it was via chemisorption except for fig leaves extract [28] and isatin derivatives [29] as well as FP, which are via physisorption.

\section{Conclusion}

FP was synthesized from underutilized SO and evaluated for its capacity to inhibit corrosion in carbon steel under acidic condition. FP was characterized using ${ }^{1} \mathrm{HNMR}$ and FTIR while the corrosion inhibition evaluation was achieved using weight loss method. The corrosion inhibition exhibited by FP was described as being through adsorption at the surface of the carbon steel, which obeyed Langmuir isotherm. The $\Delta H_{\text {ads }}^{\circ}$ for the corrosion inhibition process was $-1.088 \mathrm{~kJ} \mathrm{~mol}^{-1}$ while $\Delta S^{\circ}$ was $-0.015 \mathrm{~kJ} \mathrm{~mol}^{-1} \mathrm{~K}^{-1}$ suggesting the process to be exothermic with an activation energy of $25.606 \mathrm{~kJ} \mathrm{~mol}^{-1}$.

Acknowledgements Authors are grateful to the support received from Centre for Lipid Science and Technology, CSIR-Indian Institute of Chemical Technology, Hyderabad, India for making research facilities available.

\section{Compliance with ethical standards}

Conflict of interest The authors declare that they have no competing interests. 


\section{References}

1. Kip N, van Veen JA (2015) The dual role of microbes in corrosion. ISME J 9:542-551. https://doi.org/10.1038/ismej .2014 .169

2. Kolawole FO, Kolawole SK, Agunsoye JO, Adebisi JA, Bello SA, Hassan SB (2018) Mitigation of corrosion problems in API 5L steel pipeline-a review. J Mater Environ Sci 9:2397-2410

3. Camacho RL, Montiel E, Jayanthi N, Pandiyan T, Cruz J (2010) DFT studies of a-diimines adsorption over Fen surface $(n=1,4$, 9 and 14) as a model for metal surface coating. Chem Phys Letters 485:142-151. https://doi.org/10.1016/j.cplett.2009.12.016

4. Camacho-Mendoza RL, Aquino-Torres E, Cruz-Borbolla J, Alvarado-Rodrıguez JG, Olvera-Neria O, Narayanan J, Pandiyan T (2013) DFT analysis: $\mathrm{Fe}_{4}$ cluster and $\mathrm{Fe}(110)$ surface interaction studies with pyrrole, furan, thiophene, and selenophene molecule. Struct Chem 25:115-126. https://doi.org/10.1007/ s11224-013-0254-9

5. Gutierrez E, Rodriguez JA, Cruz-Borbolla J, Alvarado-Rodriguez JG, Thangarasu P (2016) Development of a predictive model for corrosion inhibition of carbon steel by imidazole and benzimidazole derivatives. Corros Sci 108:23-35. https://doi. org/10.1016/j.corsci.2016.02.036

6. Chigondo $M$, Chigondo $F$ (2016) Recent natural corrosion inhibitors for mild steel: an overview. J Chem, Article ID 6208937. https://doi.org/10.1155/2016/6208937

7. Vinutha MR, Venkatesha TV (2016) Review on mechanistic action of inhibitors on steel corrosion in acidic media. Port Electrochim Acta 34:157-184. https://doi.org/10.4152/pea.201603157

8. Krishnaveni K, Ravichandran J (2014) Effect of aqueous extract of leaves of Morinda tinctoria on corrosion inhibition of aluminium surface in $\mathrm{HCl}$ medium. Trans Nonferrous Met Soc China 24:2704-2712. https://doi.org/10.1016/S1003-6326(14)63401-4

9. Sığırcık G, Tüken T, Erbil M (2016) Assessment of the inhibition efficiency of 3,4-diaminobenzonitrile against the corrosion of steel. Corros Sci 102:437-445. https://doi.org/10.1016/j.corsc i.2015.10.036

10. Verma C, Ebenso EE, Bahadur I, Quraishi MA (2018) An overview on plant extracts as environmental sustainable and green corrosion inhibitors for metals and alloys in aggressive corrosive media. J Mol Liq 266:577-590. https://doi. org/10.1016/j.molliq.2018.06.110

11. Rani BEA, Basu BBJ (2012) Green inhibitors for corrosion protection of metals and alloys: an overview. Int J Corros, Article ID 380217. https://doi.org/10.1155/2012/380217

12. Marzorati S, Verotta L, Trasatti SP (2019) Green corrosion inhibitors from natural sources and biomass wastes. Molecules 24:48. https://doi.org/10.3390/molecules24010048

13. Adewuyi A, Oderinde RA, Rao BVSK, Prasad RBN (2012) Chemical composition and molecular speciation of the triacylglycerol of the oils of Lonchocarpus sericeus and Lonchocarpus cyanescens. Nat Prod Res 26:1954-1956. https://doi. org/10.1080/14786419.2011.643311

14. Fayomi OSI, Fayomi J, Elemike EE (2018) Data on anti-corrosion characteristics of eco-friendly inhibitive extract on the hot corrosion degradation trend of $A 6063$ aluminum alloy in $1.0 \mathrm{M} \mathrm{HCl}$ solution. Data Brief 19:2468-2476. https://doi. org/10.1016/j.dib.2018.04.007

15. Adewuyi A, Pereira FV (2016) Fatty alkyl tosylate from Sesamum indicum seed oil: a potential resource for the oleochemical industry. Riv Ital Delle Sostanze Grasse XCIV:161-167

16. Dasami PM, Parameswari K, Chitra S (2015) Corrosion inhibition of mild steel in $1 \mathrm{MH}_{2} \mathrm{SO}_{4}$ by thiadiazole Schiff bases. Measurement 69:195-201. https://doi.org/10.1016/j.measu rement.2015.03.025
17. Kaewprasit C, Hequet E, Abidi N, Gourlot JP (1998) Application of methylene blue adsorption to cotton fiber specific surface area measurement: part I. Methodology. J Cotton Sci 2:164-173

18. Fouda AS, Migahed MA, Atia AA, Mousa IM (2016) Corrosion inhibition and adsorption behavior of some cationic surfactants on carbon steel in hydrochloric acid solution. J Bio Tribo Corros 2:22. https://doi.org/10.1007/s40735-016-0052-1

19. Rbaa M, Galai M, El Kacimi Y, Ouakki M, Touir R, Lakhrissi B, Touhami ME (2017) Adsorption properties and inhibition of carbon steel corrosion in a hydrochloric solution by 2-(4,5-diphenyl4,5-dihydro-1h-imidazol-2-yl)-5-methoxyphenol. Port Electrochim Acta 35:323-338. https://doi.org/10.4152/pea.201706323

20. Zhang Z, Wang F, Liu Y, Wu S, Li W, Sun W, Guo D, Jiang J (2018) Molecule adsorption and corrosion mechanism of steel under protection of inhibitor in a simulated concrete solution with 3.5\% NaCl. RSC Adv 8:20648-20654. https://doi.org/10.1039/ C8RA03235A

21. Soltania N, Tavakkolia N, Kashanib MK, Mosavizadeha A, Oguziec EE, Jalalid MR (2014) Silybum marianum extract as a natural source inhibitor for 304 stainless steel corrosion in $1.0 \mathrm{M}$ $\mathrm{HCl}$. J Ind Eng Chem 20:3217-3227. https://doi.org/10.1016/j. jiec.2013.12.002

22. Ansari KR, Quraishi MA, Singh A (2015) Isatin derivatives as a non-toxic corrosion inhibitor for mild steel in $20 \% \mathrm{H}_{2} \mathrm{SO}_{4}$. Corros Sci 95:62-70. https://doi.org/10.1016/j.corsci.2015.02.010

23. Adewuyi A, Oderinde RA (2018) Synthesis of hydroxylated fatty amide from underutilized seed oil of Khaya senegalensis: a potential green inhibitor of corrosion in aluminium. J Anal Sci Technol 9:26. https://doi.org/10.1186/s40543-018-0158-9

24. Roque JM, Pandiyan T, Cruz J, Garcia-Ochoa E (2008) DFT and electrochemical studies of tris(benzimidazole-2-ylmethyl)amine as an efficient corrosion inhibitor for carbon steel surface. Corros Sci 50:614-624. https://doi.org/10.1016/j.corsci.2007.11.012

25. Obi-Egbedi NO, Obot IB, Umoren SA (2012) Spondias moubin L. as a green corrosion inhibitor for aluminium in sulphuric acid correlation between inhibitive effect and electronic properties of extracts major constituents using density functional theory. Arab J Chem 5:361-373. https://doi.org/10.1016/j.arabj c.2010.09.002

26. Obot IB, Obi-Egbedi NO, Ebenso EE, Afolabi AS, Oguzie EE (2013) Experimental, quantum chemical calculations, and molecular dynamic simulations insight into the corrosion inhibition properties of 2-(6-methylpyridin-2-yl)oxazolo [5,4-f][1, 10]phenanthroline on mild steel. Res Chem Intermed 39:1927-1948. https:// doi.org/10.1007/s11164-012-0726-3

27. Njoku DI, Ukaga I, Ikenna OB, Oguzie EE, Oguzie KL, Ibisi N (2016) Natural products for materials protection: Corrosion protection of aluminium in hydrochloric acid by Kola nitida extract. J Mol Liq 219:417-424. https://doi.org/10.1016/j.molliq.2016.03.049

28. Ibrahim TH, Abouzour M (2011) Corrosion inhibition of mild steel using Fig leaves extract in hydrochloric acid solution. Int J Electrochem Sci 6:6442-6455

29. Ansari KR, Quraishi MA, Singh A (2015) Isatin derivatives as a non-toxic corrosion inhibitor for mild steel in $20 \% \mathrm{H}_{2} \mathrm{SO}_{4}$. Corros Sci 95:62-70. https://doi.org/10.1016/j.corsci.2015.02.010

30. Tawfik SM (2015) Corrosion inhibition efficiency and adsorption behavior of $N, N$-dimethyl-4-(((1-methyl-2-phenyl-2,3-dihydro$1 \mathrm{H}$-pyrazol-4-yl)imino)methyl)- $\mathrm{N}$-alkylbenzenaminium bromide surfactant at carbon steel/hydrochloric acid interface. J Mol Liq 207:185-194. https://doi.org/10.1016/j.molliq.2015.03.036

31. Yadava M, Sinha RR, Kumar S, Bahadur I, Ebenso EE (2015) Synthesis and application of new acetohydrazide derivatives as a corrosion inhibition of mild steel in acidic medium: Insight from electrochemical and theoretical studies. J Mol Liq 208:322-332. https://doi.org/10.1016/j.molliq.2015.05.005 
32. Dasami PM, Parameswari K, Chitra S (2015) Corrosion inhibition of mild steel in $1 \mathrm{MH}_{2} \mathrm{SO}_{4}$ by thiadiazole schiff bases. Measurement 69:195-201. https://doi.org/10.1016/j.measuremen t.2015.03.025

33. Mourya P, Banerjee S, Singh MM (2014) Corrosion inhibition of mild steel in acidic solution by Tagetes erecta (Marigold flower) extract as a green inhibitor. Corros Sci 85:352-363. https://doi. org/10.1016/j.corsci.2014.04.036

34. Ammal PR, Prajila M, Joseph A (2018) Effective inhibition of mild steel corrosion in hydrochloric acid using EBIMOT, a 1, 3, 4-oxadiazole derivative bearing a 2-ethylbenzimidazole moiety: Electro analytical, computational and kinetic studies. Egypt J Pet 27:823-833. https://doi.org/10.1016/j.ejpe.2017.12.004

35. Thirumalairaj B, Jaganathan M (2016) Corrosion protection of mild steel by a new binary inhibitor system in hydrochloric acid solution. Egypt J Pet 25:423-432. https://doi.org/10.1016/j. ejpe.2015.09.002

36. Kumari PP, Shetty P, Rao SA (2017) Electrochemical measurements for the corrosion inhibition of mild steel in $1 \mathrm{M}$ hydrochloric acid by using an aromatic hydrazide derivative. Arab J Chem 10:653-663. https://doi.org/10.1016/j.arabjc.2014.09.005

37. Karthik G, Sundaravadivelu M (2016) Studies on the inhibition of mild steel corrosion in hydrochloric acid solution by atenolol drug. Egypt J Pet 25:183-191. https://doi.org/10.1016/j. ejpe.2015.04.003

38. Abdul Rahiman AFS, Sethumanickam S (2017) Corrosion inhibition, adsorption and thermodynamic properties of poly(vinyl alcohol-cysteine) in molar HCl. Arab J Chem 10:S3358-S3366. https://doi.org/10.1016/j.arabjc.2014.01.016

39. Aiad I, Shaban SM, Elged AH, Aljoboury OH (2018) Cationic surfactant based on alignate as green corrosion inhibitors for the mild steel in $1.0 \mathrm{M} \mathrm{HCl}$. Egypt J Pet 27:877-885. https://doi. org/10.1016/j.ejpe.2018.01.003
40. Verma C, Quraishi MA, Gupta NK (2018) 2-(4-\{[4-Methyl-6-(1methyl-1H-1,3-benzodiazol-2-yl)-2-propyl-1H-1,3-benzodiazol1-yl] methyl\}phenyl) benzoic acid as green corrosion inhibitor for mild steel in $1 \mathrm{M}$ hydrochloric acid. Ain Shams Eng J 9:12251233. https://doi.org/10.1016/j.asej.2016.07.003

41. Cruz-Borbolla J, Garcia-Ochoa E, Narayanan J, Maldonado-Rivas P, Pandiyan T, Vásquez-Pérez JM (2017) Electrochemical and theoretical studies of the interactions of a pyridyl-based corrosion inhibitor with iron clusters $\left(\mathrm{Fe}_{15}, \mathrm{Fe}_{30}, \mathrm{Fe}_{45}\right.$, and $\left.\mathrm{Fe}_{60}\right)$. J Mol Model 23:342. https://doi.org/10.1007/s00894-017-3510-x

42. Garcia-Ochoa E, Guzmán-Jiménez SJ, Hernández JG, Pandiyan T, Vásquez-Pérez JM, Cruz-Borbolla J (2016) Benzimidazole ligands in the corrosion inhibition for carbon steel in acid medium: DFT study of its interaction on $\mathrm{Fe}_{30}$ surface. J Mol Struct 1119:314324. https://doi.org/10.1016/j.molstruc.2016.04.057

43. Guadalupe HJ, García-Ochoa E, Maldonado-Rivas PJ, Cruz J, Pandiyan T (2011) A combined electrochemical and theoretical study of $N, N^{\prime}$-bis (benzimidazole-2yl-ethyl)-1,2-diaminoethane as a new corrosion inhibitor for carbon steel surface. J Electroanal Chem 655:164-172. https://doi.org/10.1016/j.jelec hem.2011.01.039

44. Yetri Y, Emriadi, Jamarun N, Gunawarman (2014) Corrosion inhibition efficiency of mild steel in hydrocloric acid by adding Theobroma cacao peel extract. In: International conference on biological, chemical and environmental sciences (BCES-2014), pp 14-15. http://dx.doi.org/10.15242/IICBE.C6140

Publisher's Note Springer Nature remains neutral with regard to jurisdictional claims in published maps and institutional affiliations. 